Provided for non-commercial research and education use. Not for reproduction, distribution or commercial use.

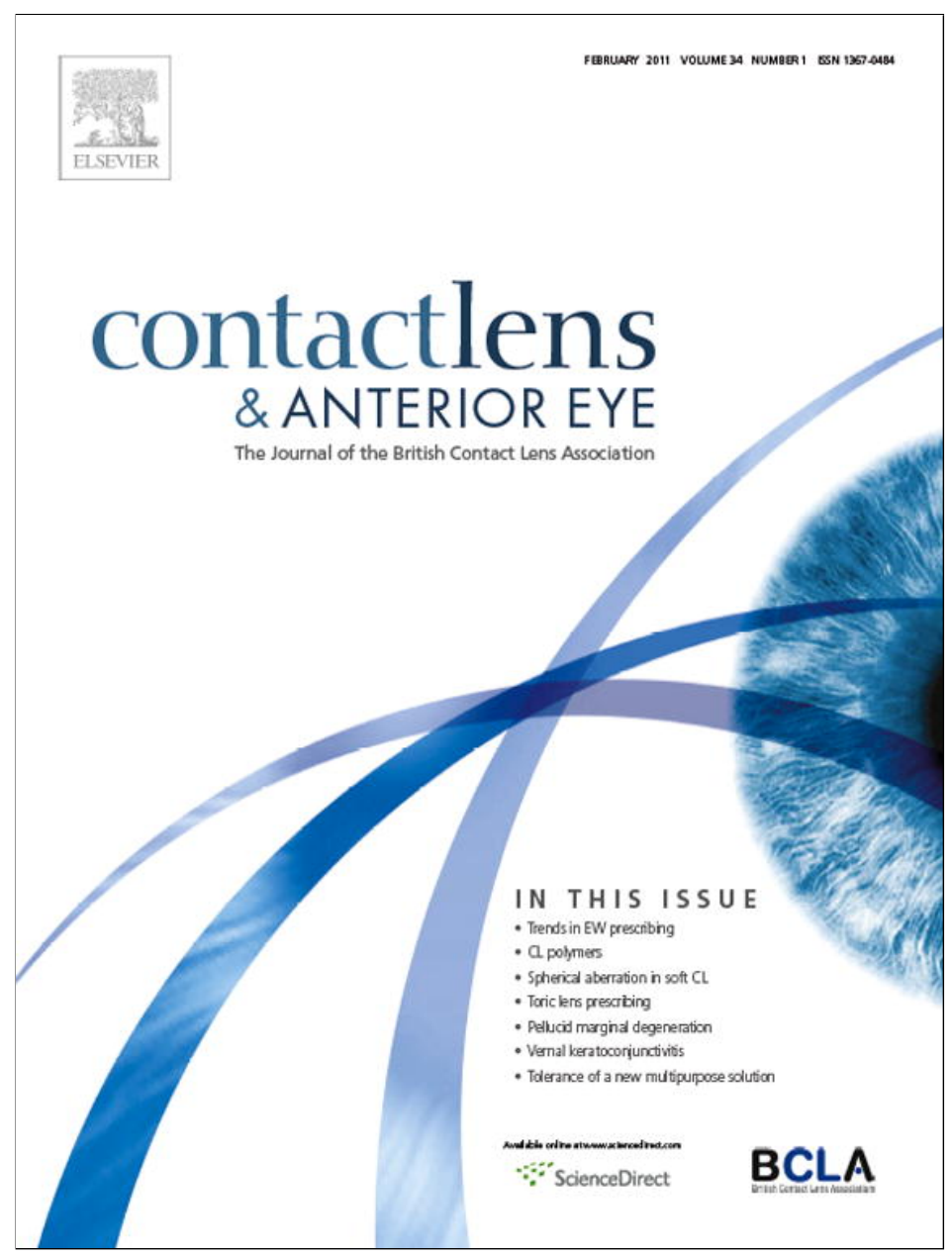

This article appeared in a journal published by Elsevier. The attached copy is furnished to the author for internal non-commercial research and education use, including for instruction at the authors institution and sharing with colleagues.

Other uses, including reproduction and distribution, or selling or licensing copies, or posting to personal, institutional or third party websites are prohibited.

In most cases authors are permitted to post their version of the article (e.g. in Word or Tex form) to their personal website or institutional repository. Authors requiring further information regarding Elsevier's archiving and manuscript policies are encouraged to visit:

http://www.elsevier.com/copyright 


\title{
Increased Langerhan cell density and corneal nerve damage in diabetic patients: Role of immune mechanisms in human diabetic neuropathy
}

\author{
M. Tavakoli ${ }^{\mathrm{a}}$, A.J.M. Boulton ${ }^{\mathrm{a}}$, N. Efron ${ }^{\mathrm{b}}$, R.A. Malik ${ }^{\mathrm{a}, *}$ \\ a Division of Cardiovascular Medicine, University of Manchester and Manchester Royal Infirmary, Manchester, M13 9NT, UK \\ ${ }^{\mathrm{b}}$ Institute of Health and Biomedical Innovation, Queensland University of Technology, Brisbane, Australia
}

\section{A R T I C L E I N F O}

\section{Keywords:}

Langerhans cells

Corneal confocal microscopy

Diabetic neuropathy

\begin{abstract}
A B S T R A C T
Aim/hypothesis: Immune mechanisms have been proposed to play a role in the development of diabetic neuropathy. We employed in vivo corneal confocal microscopy (CCM) to quantify the presence and density of Langerhans cells (LCs) in relation to the extent of corneal nerve damage in Bowman's layer of the cornea in diabetic patients.

Methods: 128 diabetic patients aged $58 \pm 1$ yrs with a differing severity of neuropathy based on Neuropathy Deficit Score (NDS $-4.7 \pm 0.28$ ) and 26 control subjects aged $53 \pm 3$ yrs were examined. Subjects underwent a full neurological evaluation, evaluation of corneal sensation with non-contact corneal aesthesiometry (NCCA) and corneal nerve morphology using corneal confocal microscopy (CCM).

Results: The proportion of individuals with LCs was significantly increased in diabetic patients (73.8\%) compared to control subjects $(46.1 \%), P=0.001$. Furthermore, LC density $\left(\mathrm{no} / \mathrm{mm}^{2}\right)$ was significantly increased in diabetic patients $(17.73 \pm 1.45)$ compared to control subjects $(6.94 \pm 1.58), P=0.001$ and there was a significant correlation with age $(r=0.162, P=0.047)$ and severity of neuropathy $(r=-0.202$, $P=0.02$ ). There was a progressive decrease in corneal sensation with increasing severity of neuropathy assessed using NDS in the diabetic patients $(r=0.414, P=0.000)$. Corneal nerve fibre density $(P<0.001)$, branch density $(P<0.001)$ and length $(P<0.001)$ were significantly decreased whilst tortuosity $(P<0.01)$ was increased in diabetic patients with increasing severity of diabetic neuropathy.

Conclusion: Utilising in vivo corneal confocal microscopy we have demonstrated increased LCs in diabetic patients particularly in the earlier phases of corneal nerve damage suggestive of an immune mediated contribution to corneal nerve damage in diabetes.
\end{abstract}

Crown Copyright @ 2010 Published by Elsevier Ltd on behalf of British Contact Lens Association. All rights reserved.

\section{Introduction}

The dominant antigen presenting cells in the cornea and ocular surface are Langerhans cells (LCs) and Dendritic cells (DCs) which are derived from the bone marrow and can stimulate both primary and secondary $\mathrm{T}$ and $\mathrm{B}$-cell responses [1]. The function and migration of DCs and LCs have been defined in numerous studies [2]. Dendritic cells were first described in the cornea by Engelmann in 1867, and have been thought to be present only in the periphery of the cornea in conditions associated with immune dysfunction such as herpetic keratitis [3,4], pseudomonas keratitis [5] and corneal allograft rejection [6]. However, recent ex

Abbreviations: CCM, corneal confocal microscopy; DCs, dendritic cells; LCs, Langerhans cells; NDS, neuropathy disability score; NCCA, non-contact corneal aesthesiometry; NFD, nerve fibre density; NBD, nerve branch density; NFL, nerve fibre length; NFT, nerve fibre tortuosity.

* Corresponding author. Tel.: +44 0161275 1196; fax: +44 01612751183.

E-mail address: rayaz.a.malik@manchester.ac.uk (R.A. Malik). vivo studies have confirmed the presence of LCs in the epithelial layer of the cornea and DCs in the anterior stroma of the central cornea [7], and revised the belief that the cornea is immune privileged and indeed is able to respond to foreign antigens and auto antigens.

Corneal confocal microscopy provides a non-invasive means to readily demonstrate LCs in healthy subjects [8-10] and dendritic cells in patients with herpes keratitis [11] and mixed bacterial keratitis [12,13]. Additionally, a range of stimuli causing corneal irritation including hypoxia, mechanical irritation, and inflammation have also been shown to lead to maturation and migration of LCs. Thus contact lens wear increases LCs and this has been demonstrated both ex vivo [14] and using corneal confocal microscopy in vivo [15]. Another recent study using corneal confocal microscopy in subjects after removal of metal foreign bodies has also shown an increase in the number of Langerhans cells in relation to acute corneal injury [16].

Over the past several years we have employed corneal confocal microscopy (CCM) to demonstrate that corneal nerve damage is directly related to the severity of somatic neuropathy in dia- 
betic patients [17-19] and in patients with Fabry disease [20]. We have also shown repair of corneal nerves six months after pancreas transplantation in patients with Type 1 diabetes [21]. We have therefore suggested that this technique may be useful for non-invasively quantifying nerve damage and repair in diabetic and perhaps other neuropathies [22]. These observations also suggest that common mechanisms may be operative in the pathogenesis of corneal and peripheral nerve damage in diabetic patients. The underlying basis for corneal nerve damage is not established. With regard to diabetic neuropathy the Rochester cohort study [23] showed that the development of neuropathy was associated with poorer glycaemic control and the development of microvascular complications. A number of metabolic risk factors such as glucose, lipids, blood pressure and BMI have also been shown to be related to the development of diabetic neuropathy [24-26]. A unifying mechanism for the development of diabetic complications has been proposed [27] but remains to be substantiated in man [28].

We have previously demonstrated that an immune mediated mechanism may act in concert with hyperglycemia to damage sensory and autonomic neurones [29]. Of relevance to the present study in the early 1980s, it was proposed that autoimmunity might contribute to the pathogenesis of diabetic neuropathy based on an association between diabetic autonomic neuropathy and iritis [30]. Since iritis itself is an immune mediated disorder with circulating immune complexes, it was suggested that the associated small fiber damage, which results in autonomic neuropathy, might have been due to autoimmunity. Thus it is of interest that using CCM an increase in the number of highly reflective cells 'presumably dendritic cells' has been demonstrated in the cornea of patients with diabetes [31].

The purpose of the present study was to quantify the presence and density of LCs in Bowman's layer in relation to the severity of corneal nerve damage and the severity of somatic neuropathy in a large group of diabetic patients and healthy subjects.

\section{Method}

\subsection{Neuropathy evaluation}

This study was approved by Central Manchester Ethics Committee and written informed consent was obtained according to the Declaration of Helsinki. All patients underwent a detailed clinical history and examination. If the patients had neuropathy for any other reason apart from diabetes or had history of contact lens wear or corneal surgery they were excluded from the study. The neuropathy disability score (NDS) was used to grade the severity of neuropathy. NDS is based on a clinical scoring system obtained from a neurological examination which defines abnormalities of vibration perception using a tuning fork, pin prick perception and temperature perception as well as the presence or absence of ankle reflexes, producing a score ranging from 0 to 10 [32]. Based on the NDS score, diabetic patients were classified into the following four groups: NDS $=0-2$ : 'no neuropathy'; NDS = 3-5: 'mild neuropathy'; NDS=6-8: 'moderate neuropathy'; and NDS=9-10: 'severe neuropathy'.

\subsection{Corneal sensitivity}

Corneal sensitivity was quantified using a non-contact corneal aesthesiometer (NCCA) (Glasgow, Caledonian University, UK) which uses a puff of air on the centre of the cornea, lasting $0.9 \mathrm{~s}$ and exerting a force expressed in millibars (mbars) [33]. The coefficient of variation for NCCA is $5.6 \%$.

\subsection{Corneal confocal microscopy}

Patients underwent examination with a Tomey Confoscan corneal confocal microscope model P4 (Erlangen, Germany). One eye of each subject was selected at random for examination. Several scans of the entire depth of the cornea were recorded by turning the fine focus of the objective lens backwards and forwards for approximately 2 min to acquire satisfactory images of all corneal layers providing en face two dimensional images with a lateral resolution of approximately $1-2 \mu \mathrm{m}$ and final image size of 768 pixels $\times 576$ pixels. On average, three to five high quality images of Bowman's layer were used to quantify both nerve fibre morphology and Langerhan cell density in all patients and control subjects and the average results of all these images calculated. This layer is of particular relevance for defining neuropathic changes since it is the location of the main nerve plexus that supplies the overlying corneal epithelium. The investigator who examined the cornea with the corneal confocal microscope and undertook morphometric measurements of the images was masked with respect to the identity of the patient. For morphometric measurements of corneal nerves four parameters were quantified [17-19,34]: corneal nerve fiber density (NFD)-total number of major nerves $/ \mathrm{mm}^{2}$; nerve fiber length (NFL)-total length of all nerve fibers and branches $\left(\mathrm{mm} / \mathrm{mm}^{2}\right)$; nerve branch density (NBD)-number of branches emanating from major nerve trunks $/ \mathrm{mm}^{2}$ and nerve fibre tortuosity (NFT) was computed using a novel mathematical approach which was termed 'tortuosity coefficient' (TC).

As anatomically Bowman's layer is an otherwise acellular layer containing c-nerve fibres, it is easy to distinguish other cells in this layer of the cornea. First, the presence or absence of highly reflective cells was assessed and then the number of highly reflective cells 'Langerhans cells' (Fig. 1) were counted manually in each image frame from Bowman's layer of the cornea in diabetic patients and healthy volunteers and the final density was derived as the number of cells in the area of frame assessed in square millimetres (number $/ \mathrm{mm}^{2}$ ) [10].

\subsection{Statistical analysis}

SPSS 11.05 .0 for Windows was used to compute the results. Analysis included descriptive and frequency statistics. One-way analysis of variance (ANOVA) with Scheffe Post hoc tests was used to study differences between means. Pearson's test was used to analyze correlations between potentially related variables.

\section{Results}

\subsection{Clinical details}

128 predominantly Type 2 diabetic patients aged $58 \pm 1$ yrs with a mean duration of diabetes $15 \pm 1$ yrs were studied. The patients were stratified in accordance with the severity of somatic neuropathy using the NDS: none $(1.29 \pm 0.14, n=42)$, mild $(3.86 \pm 0.11$, $n=37)$, moderate $(7.17 \pm 0.19, n=24)$ and severe $(9.72 \pm 0.09$, $n=25$ ) and compared to 26 age-matched control subjects ( $53 \pm 3$ yrs). The age, type of diabetes and HbA1c were well matched between the different groups with differing severity of neuropathy. Diabetes duration and as expected the NDS increased with increasing neuropathic severity (Table 1 ).

\subsection{Langerhans cells}

The proportion of individuals with LCs was significantly increased in diabetic patients $(73.8 \%)$ compared to control subjects (46.1\%), $P=0.001$. Furthermore LC density was significantly increased in diabetic patients compared to control subjects 

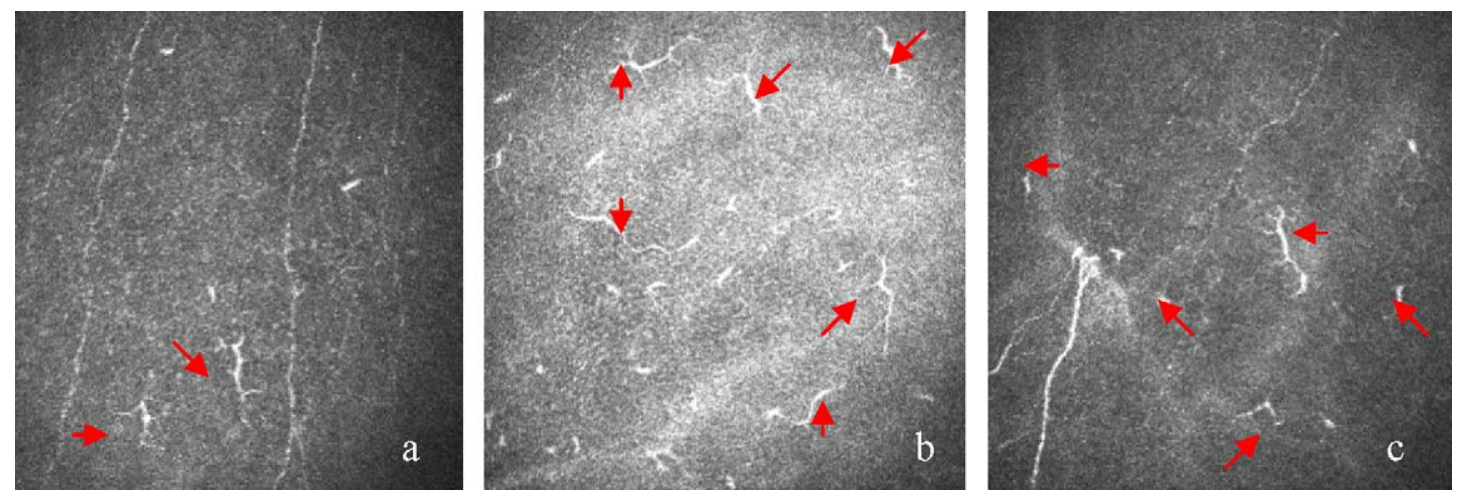

Fig. 1. Images from Bowman's layer of the cornea with highly reflective cells 'presumably Langerhans cells': (a) control subject, (b) diabetic patient with mild neuropathy and (c) diabetic patient with severe neuropathy.

$\left(17.73 \pm 1.45 \mathrm{no} / \mathrm{mm}^{2}\right.$ vs $\left.6.94 \pm 1.58 \mathrm{no} / \mathrm{mm}^{2}, P=0.001\right)$ (Table 1 and Fig. 2). With regard to the severity of neuropathy, LC density was significantly increased in diabetic patients with no neuropathy $(P=0.04)$ and mild neuropathy $(P=0.004)$. However with progression of nerve damage, diabetic patients with moderate $(P=0.393)$ and severe $(P=0.932)$ neuropathy showed a reduction in the LC density which was not significantly different from control subjects (Table 1 and Fig. 2). There was no significant difference between patients with Type 1 and Type 2 diabetes, with LCs being present in $68 \%$ of patients with Type I and $72 \%$ of patients with Type 2 diabetes. The LC density was significantly increased in Type I $(P=0.03)$ and Type $2(P=0.009)$ diabetic patients compared to control subjects but did not differ between Type $1\left(18.93 \pm 3.85 \mathrm{no} / \mathrm{mm}^{2}\right)$ and Type $2\left(17.48 \pm 1.57 \mathrm{no} / \mathrm{mm}^{2}\right)$ diabetic patients.

\subsection{Corneal sensation}

There was a progressive increase in the NCCA threshold indicative of a decrease in corneal sensation with increasing severity of neuropathy in diabetic patients (Table 1 ).

\subsection{Corneal nerve fibres}

Corneal nerve fibre density $(P<0.001)$, branch density $(P<0.001)$ and length $(P<0.001)$ were significantly decreased whilst tortuosity $(P<0.01)$ was increased in diabetic patients with increasing severity of neuropathy (Table 1 ).

\subsection{Correlations}

Despite the reduction in LCs in those with more severe neuropathy there was a significant correlation between the density of LCs and severity of neuropathy assessed by NDS $(r=-0.02$, $P=0.02$ ). There was also a significant correlation between LC density and age $(r=0.162, P=0.04)$. There was no significant correlation between LC density and duration of diabetes $(r=-0.082, P=0.36)$, or HbA1c $(r=0.145, P=0.09)$. Gender had no effect on the number of LCs. In this group of patients, there was also a significant correlation between NDS and NFD $(r=-0.341, P=0.000)$, NBD $(r=-0.311$, $P=0.000)$, NFL $(r=-0.430, P=0.000)$, NFT $(r=0.217, P=0.02)$ and NCCA $(r=0.414, P=0.000)$. However, there was no significant correlation between LC density and corneal sensitivity or corneal nerve morphology.

\section{Discussion}

The key finding is that the density of LCs was significantly increased in diabetic patients, particularly in those with no or mild neuropathy which then decreased in those with moderate and severe neuropathy, though still remained above control values. This suggests that LCs may play a role in the early phase of nerve damage and then this is maintained by other established mechanisms [28]. However, as there was no correlation between glycaemic control (HbA1c) and LC density this suggests that the increase in these cells may be a hyperglycemia independent mech-
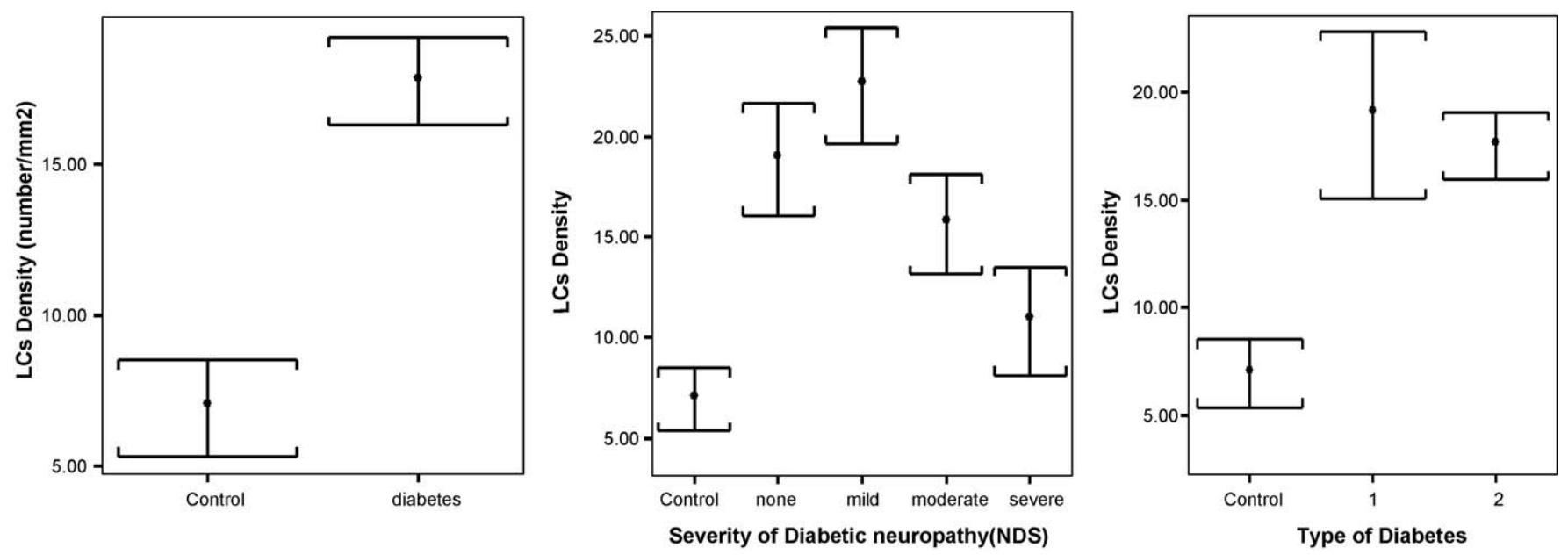

Fig. 2. Density of Langerhans cells: (a) in diabetic patients compared to control subjects $(P=0.001)$, (b) in diabetic patients according to severity of neuropathy (control vs none $P=0.045$, vs mild $P=0.004$, vs moderate: $P=0.393$, vs severe: $P=0.932$ ) and $(c)$ comparing patients with type I and type II diabetes. (For each group, horizontal bars illustrate the mean and vertical bars illustrate the SE.) 
Table 1

Demographic details, LC density, corneal sensation and CCM morphology in (a) diabetic patients and control subjects and (b) diabetic patient subgroups according to the severity of neuropathy.

\begin{tabular}{|c|c|c|c|c|c|c|}
\hline \multicolumn{3}{|l|}{ (a) } & \multicolumn{4}{|l|}{ (b) } \\
\hline & Control & Diabetes & None & Mild & Moderate & Severe \\
\hline Number & 26 & 128 & 42 & 37 & 24 & 25 \\
\hline Age (yrs) & $53 \pm 3$ & $58 \pm 1$ & $57 \pm 2$ & $58 \pm 2$ & $58 \pm 2$ & $61 \pm 2$ \\
\hline $\operatorname{Sex}(F / M)$ & $16 / 10$ & $36 / 92$ & $18 / 24$ & $10 / 27$ & $4 / 20$ & $4 / 21$ \\
\hline Type I/II & - & $22 / 106$ & $2 / 40$ & $5 / 32$ & $10 / 14$ & $5 / 20$ \\
\hline HbA1c (\%) & $\sim 5.8$ & $8.16 \pm 0.14$ & $7.88 \pm 0.19$ & $8.29 \pm 0.31$ & $8.08 \pm 0.21$ & $8.54 \pm 0.43$ \\
\hline $\operatorname{NDS}(0-10)$ & 0 & $4.79 \pm 0.29$ & $1.29 \pm 0.14^{\$}$ & $3.86 \pm 0.11^{\$}$ & $7.17 \pm 0.19^{\$}$ & $9.72 \pm 0.09^{\$}$ \\
\hline LC (presence/absence) ${ }^{*}$ & $48 \%(12 / 14)$ & $72 \%(93 / 35)$ & $73 \%(31 / 11)$ & $83 \%(31 / 6)$ & $79 \%(19 / 5)$ & $48 \%(12 / 13)$ \\
\hline LC density $\left(\mathrm{no} / \mathrm{mm}^{2}\right)^{*}$ & $6.94 \pm 1.58$ & $17.73 \pm 1.45$ & $18.84 \pm 2.7^{\dagger}$ & $22.51 \pm 2.89$ & $15.61 \pm 2.48$ & $10.83 \pm 2.69$ \\
\hline NCCA (mbar) ${ }^{*}$ & $0.72 \pm 0.02$ & $1.48 \pm 0.10$ & $1.15 \pm 0.07$ & $1.27 \pm 0.10$ & $1.55 \pm 0.20$ & $2.43 \pm 0.44$ \\
\hline $\mathrm{NFD}\left(\mathrm{no} / \mathrm{mm}^{2}\right)^{*}$ & $40.78 \pm 2.64$ & $27.02 \pm 1.16$ & $31.86 \pm 2.16$ & $27.85 \pm 2.00$ & $24.43 \pm 3.12$ & $18.11 \pm 1.6 \$$ \\
\hline $\mathrm{NBD}\left(\mathrm{no} / \mathrm{mm}^{2}\right)^{*}$ & $26.47 \pm 2.22$ & $14.55 \pm 1.19$ & $19.40 \pm 1.93$ & $13.62 \pm 2.01^{\Phi}$ & $13.97 \pm 3.3$ & $6.13 \pm 1.73^{\$}$ \\
\hline $\mathrm{NFL}\left(\mathrm{mm} / \mathrm{mm}^{2}\right)^{*}$ & $8.76 \pm 0.57$ & $5.71 \pm 0.30$ & $7.60 \pm 0.59$ & $5.31 \pm 0.50^{\$}$ & $4.44 \pm 0.52^{\$}$ & $3.49 \pm 0.35^{\$}$ \\
\hline NFT (TC $)^{\ddagger}$ & $19.77 \pm 1.35$ & $25.69 \pm 1.05$ & $24.21 \pm 2.09$ & $24.38 \pm 1.62$ & $26.86 \pm 2.09$ & $31.23 \pm 2.39$ \\
\hline
\end{tabular}

Data are expressed as mean \pm SEM for diabetic patients and control subjects. Abbreviations: LCs: Langerhans cells; NDS: neuropathy deficit score; NCCA: non-contact corneal aesthesiometer; NFD: nerve fibre density; NBD: nerve branch density; NFL: nerve fibre length; NFT: nerve fibre tortuiosity; TC: tortuiosity coefficient.

* Statistically significant difference between diabetic patients and controls using ANOVA: $P<0.001$.

\$ Statistically significant difference between diabetic patients and controls using ANOVA: $P<0.01$.

Post hoc results show a significant difference from control subjects and diabetic patients with different severity of neuropathy: $P<0.05$.

I Post hoc results show a significant difference from control subjects and diabetic patients with different severity of neuropathy: $P<0.01$.

$\$$ Post hoc results show a significant difference from control subjects and diabetic patients with different severity of neuropathy: $P \leq 0.001$.

anism. Although one might expect for there to be greater immune mediated involvement in patients with Type 1 diabetes, a sub analysis between patients with Type 1 and Type 2 diabetes showed no significant difference in LC density. We also confirm in a larger group of diabetic patients our previous observations demonstrating a progressive loss of corneal sensation [33] and abnormalities in corneal nerve morphology [17,18,34].

Several in vivo studies have suggested that 'bright irregular particles' [35], 'undefined dendritic structures' [11] and cellular structures $[10,15]$ represent LCs in the cornea. Thus using corneal confocal microscopy LCs are seen as bright corpuscular particles with DC morphology and a diameter of up to $15 \mu \mathrm{m}$ [15]. An in vitro study using confocal microscopy on the corneal epithelium of mice has demonstrated the phenotype and distribution of MHC class II negative LCs in the central and paracentral areas, with MHC class II positive LCs in the limbus and corneal periphery [36]. They have been found to be mainly located in the periphery suggesting that there was lack of dendritic cells in the centre [37]. Most previous in vivo studies $[10,11,35]$ have reported the location of the LCs to be beneath the basal epithelial cells between the nerve fibres, as in our study.

Studies of LCs in diabetes are limited using CCM with one study showing an increase in the number of highly reflective presumably 'dendritic cells' in the cornea of diabetic patients [31]. To our knowledge, the present study is the first in vivo study identifying LCs in the Bowman's layer of the cornea of diabetic patients. Differentiating LC bodies lacking dendrites from LCs with small dendritic processes forming a local network, and LCs forming 'wire netting' via long interdigitating dendrites in Bowman's layer of the cornea using the Tomey light Confoscan is difficult [38] and this may explain some of the discrepancies in terms of the densities of LCs. The presence of LCs in $47 \%$ of healthy subjects is in agreement with Zhiviov et al. [10,15], who showed that $31 \%$ of their normal cases had LCs. Also in the present study LCs were absent in $28 \%$ of diabetic patients and in $53 \%$ of control subjects which was similar to that in diabetic patients with severe neuropathy (52\%). Although the presence of LCs is in agreement with a previous study [10], the density of LCs is much lower in our study compared to other studies. This clearly reflects alternative means of detecting LCs, thus using in vitro techniques of immunofluorescence to detect HLA-DR antigens surface densities of LCs vary from 15 to 20 cells $/ \mathrm{mm}^{2}$ in the peripheral cornea of guinea pigs and rats to
$50-100$ cells $/ \mathrm{mm}^{2}$ and $75-150$ cells $/ \mathrm{mm}^{2}$ in the peripheral cornea of mice and humans, respectively [39]. In vivo CCM has shown an average value of approximately 98 cells $/ \mathrm{mm}^{2}$ in the periphery of the cornea, and 34 cells $/ \mathrm{mm}^{2}$ in the central cornea of the human. Our lower values may reflect the fact that we focused principally on Bowman's layer which is known to have a lower density of LCs compared to the epithelial layer [36,39]. In addition we employed the Tomey CCM which has been shown to underestimate LC density compared to newer CCMs such as the Heidelberg HRT III CCM $[10,15]$.

In conclusion these data provide support for a potential immune mediated basis of corneal nerve damage. Given our previous studies showing a correlation between corneal and intraepidermal nerve fibre loss in diabetic patients [37] this provides further support for a common immune mediated mechanism for human diabetic neuropathy and adds to the body of previous data suggesting an immune component in the pathogenesis of human diabetic neuropathy $[29,30]$. In the future the use of more powerful in vivo confocal microscopes such as the HRT-II may help further differentiate the role of LCs in the development and progression of nerve damage in diabetes. Furthermore, mechanistic studies are warranted to define the basis of this immune mediated damage to perhaps help develop therapeutic strategies to prevent early nerve fibre damage.

\section{Disclosure}

The authors have no conflict of interest to disclose.

\section{Acknowledgments}

This work was supported by Juvenile Diabetes Research Foundation International Grant 5-2002-185 and National Eye Institute Grant 1 R01 NS46259-01.

\section{References}

[1] Dana MR. Corneal antigen-presenting cells: diversity, plasticity, and disguise: the Cogan lecture. Invest Ophthalmol Vis Sci 2004:45:722-7, 721.

[2] Steinman RM, Cohn ZA. Identification of a novel cell type in peripheral lymphoid organs of mice. I. Morphology, quantitation, tissue distribution. J Exp Med 1973;137:1142-62. 
[3] Jager MJ, Atherton S, Bradley D, Streilein JW. Herpetic stromal keratitis in mice: less reversibility in the presence of Langerhans cells in the central cornea. Curr Eye Res 1991;10(Suppl):69-73.

[4] Miller JK, Laycock KA, Nash MM, Pepose JS. Corneal Langerhans cell dynamics after herpes simplex virus reactivation. Invest Ophthalmol Vis Sci 1993;34:2282-90.

[5] Hazlett LD. Pathogenic mechanisms of P. aeruginosa keratitis: a review of the role of T cells, Langerhans cells, PMN, and cytokines. DNA Cell Biol 2002;21:383-90.

[6] Niederkorn JY, Peeler JS, Ross J, Callanan D. The immunogenic privilege of corneal allografts. Reg Immunol 1989;2:117-24.

[7] Hamrah P, Dana MR. Corneal antigen-presenting cells. Chem Immunol Allergy 2007;92:58-70.

[8] Auran JD, Koester CJ, Kleiman NJ, Rapaport R, Bomann JS, Wirotsko BM et al. Scanning slit confocal microscopic observation of cell morphology and movement within the normal human anterior cornea. Ophthalmology 1995;102:33-41.

[9] Patel DV, McGhee CN. Mapping of the normal human corneal sub-basal nerve plexus by in vivo laser scanning confocal microscopy. Invest Ophthalmol Vis Sci 2005;46:4485-8.

[10] Zhivov A, Stave J, Vollmar B, Guthoff R. In vivo confocal microscopic evaluation of Langerhans cell density and distribution in the normal human corneal epithelium. Graefes Arch Clin Exp Ophthalmol 2005;243:1056-61.

[11] Rosenberg ME, Tervo TM, Muller LJ, Moilanen JA, Vesaluoma MH. In vivo confocal microscopy after herpes keratitis. Cornea 2002;21:265-9.

[12] Su PY, Hu FR, Chen YM, Han JH, Chen WL. Dendritiform cells found in central cornea by in-vivo confocal microscopy in a patient with mixed bacterial keratitis. Ocul Immunol Inflamm 2006;14:241-4.

[13] Kawamoto KCT, Takahashi N, Nishida T. In vivo observation of Langerhans cells by laser confocal microscopy in Thygeson's superficial punctate keratitis. Mol Vis 2009;29:1456-62.

[14] Hazlett LD, McClellan SM, Hume EB, Dajcs JJ, O'Callaghan RJ, Willcox MD. Extended wear contact lens usage induces Langerhans cell migration into cornea. Exp Eye Res 1999;69:575-7.

[15] Zhivov A, Stave J, Vollmar B, Guthoff R. In vivo confocal microscopic evaluation of Langerhans cell density and distribution in the corneal epithelium of healthy volunteers and contact lens wearers. Cornea 2007;26:47-54.

[16] Resch MD, Imre L, Tapaszto B, Nemeth J. Confocal microscopic evidence of increased Langerhans cell activity after corneal metal foreign body removal. Eur J Ophthalmol 2008;18:703-7.

[17] Kallinikos P, Berhanu M, O’Donnell C, Boulton AJ, Efron N, Malik RA. Corneal nerve tortuosity in diabetic patients with neuropathy. Invest Ophthalmol Vis Sci 2004;45:418-22.

[18] Malik RA, Kallinikos P, Abbott CA, van Schie CH, Morgan P, Efron N, et al. Corneal confocal microscopy: a non-invasive surrogate of nerve fibre damage and repair in diabetic patients. Diabetologia 2003;46:683-8.

[19] Tavakoli MQC, Abbott C, Kallinikos P, Marshall A, Finnigan J, Morgan P, et al. Corneal confocal microscopy: a novel noninvasive test to diagnose and stratify the severity of human diabetic neuropathy. Diabetes Care 2010;33: 1792-7.

[20] Tavakoli MMA, Thompson L, Margaret Kenny M, Waldek S, Efron N, Malik RA. Corneal confocal microscopy: a novel non-invasive means to diagnose neuropathy in patients with Fabry disease. Muscle and Nerve 2009;40: 976-84.
[21] Mehra S, Tavakoli M, Kallinikos PA, Efron N, Boulton AJ, Augustine T, et al. Corneal confocal microscopy detects early nerve regeneration after pancreas transplantation in patients with type 1 diabetes. Diabetes Care 2007;30:2608-12.

[22] Hossain P, Sachdev A, Malik RA. Early detection of diabetic peripheral neuropathy with corneal confocal microscopy. Lancet 2005;366:1340-3.

[23] Dyck PJ, Davies JL, Litchy WJ, O'Brien PC. Longitudinal assessment of diabetic polyneuropathy using a composite score in the Rochester Diabetic Neuropathy Study cohort. Neurology 1997;49:229-39.

[24] Adler AI, Boyko EJ, Ahroni JH, Stensel V, Forsberg RC, Smith DG. Risk factors for diabetic peripheral sensory neuropathy. Results of the Seattle Prospective Diabetic Foot Study. Diabetes Care 1997;20:1162-7.

[25] Forrest KY, Maser RE, Pambianco G, Becker DJ, Orchard TJ. Hypertension as a risk factor for diabetic neuropathy: a prospective study. Diabetes 1997:46:665-70.

[26] Tesfaye S, Chaturvedi N, Eaton SE, Ward JD, Manes C, Ionescu-Tirgoviste C, et al. Vascular risk factors and diabetic neuropathy. N Engl J Med 2005;352:341-50.

[27] Brownlee M. Biochemistry and molecular cell biology of diabetic complications. Nature 2001;414:813-20.

[28] Tomlinson DR, Gardiner NJ. Glucose neurotoxicity. Nat Rev Neurosci 2008;9:36-45.

[29] Pittenger GL, Malik RA, Burcus N, Boulton AJ, Vinik AI. Specific fiber deficits in sensorimotor diabetic polyneuropathy correspond to cytotoxicity against neuroblastoma cells of sera from patients with diabetes. Diabetes Care 1999;22:1839-44.

[30] Guy RJ, Richards F, Edmonds ME, Watkins PJ. Diabetic autonomic neuropathy and iritis: an association suggesting an immunological cause. Br Med J (Clin Res Ed) $1984 ; 289: 343-5$.

[31] Popper M, Quadrado MJ, Morgado AM, Murta JN, Van Best JA, Muller LJ. Subbasal Nerves and Highly Reflective Cells in Corneas of Diabetic Patients: in vivo Evaluation by Confocal Microscopy. Invest Ophthalmol Vis Sci 2005;46. E-Abstract 879 .

[32] Young MJ, Boulton AJ, MacLeod AF, Williams DR, Sonksen PH. A multicentre study of the prevalence of diabetic peripheral neuropathy in the United Kingdom hospital clinic population. Diabetologia 1993;36:150-4.

[33] Tavakoli M, Kallinikos PA, Efron N, Boulton AJ, Malik RA. Corneal sensitivity is reduced and relates to the severity of neuropathy in patients with diabetes. Diabetes Care 2007;30:1895-7.

[34] Quattrini C, Tavakoli M, Jeziorska M, Kallinikos P, Tesfaye S, Finnigan J, et al. Surrogate markers of small fiber damage in human diabetic neuropathy. Diabetes 2007;56:2148-54.

[35] Rosenberg ME, Tervo TM, Petroll WM, Vesaluoma MH. In vivo confocal microscopy of patients with corneal recurrent erosion syndrome or epithelial basement membrane dystrophy. Ophthalmology 2000;107:565-73.

[36] Hamrah P, Zhang Q, Liu Y, Dana MR. Novel characterization of MHC class IInegative population of resident corneal Langerhans cell-type dendritic cells. Invest Ophthalmol Vis Sci 2002;43:639-46.

[37] Hamrah P, Liu Y, Zhang O, Dana MR. Alterations in corneal stromal dendritic cell phenotype and distribution in inflammation. Arch Ophthalmol 2003;121:1132-40.

[38] de Jong MC, Blanken R, Nanninga J, Van Voorst Vader PC, Poppema S. Defined in situ enumeration of T6 and HLA-DR expressing epidermal Langerhans cells: morphologic and methodologic aspects. J Invest Dermatol 1986;87:698-702.

[39] Gillette TE, Chandler JW, Greiner JV. Langerhans cells of the ocular surface. Ophthalmology 1982;89:700-11. 